\title{
Efficacy of Learning Modules to Enhance Study Skills
}

\author{
Kenneth M. Cramer, Craig Ross, Lisa Plant, Rebecca Pschibul \\ University of Windsor
}

\begin{abstract}
A key roadblock in students' success in higher education involves a lack of preparedness. That is, students may be ill-equipped for demands inherent in the pursuit of an academic degree (such as managing one's time, taking class notes, and preparing for examinations). To address these missing resources, educators have turned to offering students learning modules as face-to-face or online educational supplements. Two studies were conducted to investigate both the usefulness and effectiveness of learning modules for students in an introductory psychology course. Specifically, we compared students' midterm and examination scores by those who received two modular skill sets (both examination-taking strategies and time management) before or after the course midterm. Students' relative levels of each of perceived motivation, interest, and effectiveness of the modules were measured at the conclusion of the course. Results showed a significant association between module receipt and improved performance on the midterm and final examination, regardless of when the modules were presented (that is, either before or after the midterm). Additionally, students who completed the modules indicated that they enjoyed them, scoring significantly higher on their final examination. Based on these results, we encourage instructors and educational developers to design and offer learning modules to students (in first-year courses in particular) to enhance student success across their college or university experience.
\end{abstract}

\section{Introduction}

Many students acquire basic learning skills through special workshops, previous learning experiences, classroom exercises, university counselling services, and tutoring (namely from peers or teachers). However, not all students enjoy these opportunities, and the extent of learning development that occurs (despite enrollment criteria set by administrators) will necessarily vary widely across the student population. Previous research has shown that modules -- that provide much needed social, academic, and adjustment skills including time management, examination strategies, reading, and note-taking techniques -- increase student success through coursework [3, 7, 13, 15, 16], thereby creating a useful framework from which students can learn effectively. There is reason to believe as well that students will make use of resources provided to them [5]; that is to say, students who acquire these modular skills prior to their midterm should apply them to any given evaluation. The present study aims to evaluate the effectiveness and utility of learning modules in a classroom.

The adjustment period from high school to university or college is often a difficult transition for many post-secondary students. Along with the differences between the learning environments and expectations, students must also learn to firmly grasp and take responsibility for their own learning. Essentially students must become active participants in their own learning process. In the past, statistics have shown that approximately $48 \%$ of first year students were doing less well academically than initially expected and that only around $7 \%$ of these student's expectations matched their actual experience regarding academic requirements and demands [8]. Thus, this presents further evidence for the ongoing need of new post-secondary students in navigating the university learning environment in order to reach their full academic potential.

In a nutshell, learning modules represent either face-to-face or online units or tools by which educators can broadcast instruction on a given topic. Those that help to foster student skills and success may include time management (viz. showing students how to more effectively plan their timetable, how to include both recreation and work, and how to set reachable goals in a reasonable span of time), examination preparation (viz. showing how distributed practice is more effective than mass practice or cramming, how a reasonable study schedule for an upcoming midterm might span two or more weeks), and examination-taking strategies (viz. showing how to complete easy questions first, how to draw information from other questions in an effort to solve an earlier item, how to cover the responses to a multiple choice stem and anticipate what the correct answer might be), etc. Of course, 
learning items may target domain-specific content, so that a module might prepare students for the graduate record examination, or either law or medical school entrance tests; or proficiency and professional standards tests that might be required in practical fields such as nursing or pharmacy. In short, a learning module represents an especially flexible tool by which instructors may deliver much needed content, or even missed learning from prior years in the education system.

Instilling and developing learning skills in university students is a goal shared by many university professors in higher education who seek to prepare their students for postgraduate, real-world situations. The unfortunate reality is that, despite the necessity of these learning skills, many incoming university students lack the ability to learn effectively. Additionally, many professors have perhaps not been educated in the specific manner in which they can foster the development of such learning skills, and thus lack a clear framework or model for how to cultivate these skills in students (e.g., critical thinking skills) [1]. Professors often also do not have the allocated time to spend with first-year students to ensure that each has the necessary skills to learn successfully. It has further been recommended that faculty members and counsellors should emphasize student participation in furthering their learning skills to improve student academic success, and moreover to buffer the effect of academic stress on students [14].

Researchers have conducted studies investigating the beneficial effects of offering programs, workshops, and classroom lectures on varying learning skills to students in order to determine the usefulness of such assistance in enhancing academic performance. For example, these studies have looked at time management practices [19], critical thinking skills and strategies for learning success in relation to their effects on anxiety [1], stress life satisfaction, motivation, academic performance, and overall coping strategies [9]. These studies took place in multiple settings such as virtual classrooms and learning course-specific modules online lecture classrooms and working at home and examined varying student populations such as high school [6], college $[2,11,12]$, undergraduate university (17) and both part-time and full-time students [13], as well as working professionals [11].

The benefits that accompany the acquisition of time management skills, examination-taking, and textbook-reading strategies will necessarily impact higher education in several ways. Recently, growing emphasis has been placed in the modern education system on time management issues faced by students and thus studies on student attitudes and behaviours related to time and its management are being conducted [19]. For instance, numerous studies have demonstrated that time management skills are directly related to successful academic performance $[2,12,19,20]$; moreover, effective time management strategies increase academic performance [4]. Students who do not have such skills are often found to (a) manage their time poorly, (b) have difficulty with allocating time properly for homework, (c) cram for examinations, and (d) fail to meet important deadlines. All of these detriments influence and even augment academic stress, but further impede academic performance [10]. It is also widely understood that, given the continuously changing educational environment, time management is becoming increasingly important. Education offered through e-learning and virtual teaching are gaining popularity; and for such programs where face-to-face time with instructors is compromised or limited, time management becomes crucial for students who are responsible for scheduling their own time for learning [13]. Thus, this example demonstrates one of the many ways students can benefit from learning how to learn, study, plan, and use time more effectively. Researchers [2] examined the effects of time-management practices on college grades, and determined that effective time-management practices were significant predictors of grade point average and ultimately that these practices are positive influences of college achievement. One study [20] further looked at time management skills but more specifically at its effects on self-efficacy and academic performance. They found that training of time management skills was influential in increasing academic performance and self-efficacy. Other researchers [12] also conducted a study with students assessing their time management behaviours (with the use of a questionnaire), attitudes, stress, and selfperceptions of performance and grade point average. They found that students who perceived control of their time also reported significantly greater evaluations of their performance and work as well as greater life satisfaction and fewer somatic tensions among other variables. For a further review of studies investigating students' time-management skills [19]. Overall, what these studies collectively indicate is that skills such as time-management, do increase academic performance and therefore ought to be taught to students in an effective manner in order to ensure further academic success in the context of higher learning.

Previous research has suggested that more objective measures of performance, such as grades and test scores, should be used in future research instead of self-reported performance [12], and thus the current research acquired such information of students to determine performance improvement. The present study compared the midterm and final examination performance of students who received two modular skill sets (text reading and examination strategies) either before or after the midterm evaluation. Relative motivation, interest, and 
perceived effectiveness were also assessed. As an important benchmark, student test performance was also compared to those students who did not complete either of the two modules. Secondarily, we also wished to determine more definitively when the two learning modules would be optimally delivered for maximal effectiveness - either before or after a midterm test. On the one hand, there is reason to believe that students will make use of resources provided to them [18]. As such, students who acquire these modular skills prior to the midterm will be able to apply them to the present evaluation, though we anticipate that they may not be especially motivated to learn the skills. Conversely, students who already have an evaluation of their performance in the course should be more motivated to learn the materials presented in the modules and should subsequently perform better on future evaluations (i.e., the final examination). Ultimately, it is expected that the students who engage in these learning modules will see their subsequent performance positively improved over time. The activities included in the learning models allow an opportunity for students to practice and receive some feedback on the use of the learning strategies and to transfer material to actual learning environments. The essential goal of the learning modules is to provide students with procedures to follow and resources to use to either help avoid or cope with academic difficulties and the stresses inherent with university life.

The learning modules provided information on learning strategies to better prepare students to meet the academic challenges of post-secondary studies. The objectives of these models were to increase the students' knowledge and understanding of learning and study skills as well as to increase their ability to use the learning strategies through practice. Familiarizing and training students to implement time management and examination strategies can be further reinforced when the teaching of skills is part of the meta-curriculum in content-area courses as is the case with these models being presented in the introductory psychology courses.

\section{Study-1: Method}

\subsection{Participants}

The flagship first-year Introductory Psychology class at a mid-sized Canadian university served as an in-situ data collection opportunity. The course is offered in two large daytime sections taught by the same instructor $(n=825)$, plus two evening sections taught by separate instructors $(n=278$; none of these students received learning modules). Students in the two large daytime sections were divided (by selfselection) into those who completed the assigned learning modules $(n=398,132$ male and 265 female, with 1 unspecified) and those who did not $(n=427)$.

Since participant age (and maturity) may have played a role in the success of learning modules, we evaluated group differences in age by sex and course section. The overall age across all participants was 20.64 years $(\mathrm{SD}=6.26)$, and this varied nonsignificantly by sex (averages of 20.77 and 20.59 for male and female respondents, respectively; $p>$ $.05)$.

Two modules (viz. time management and examination strategies) were presented in 25-minute face-to-face instructional sessions (more specifically, during their prescribed laboratory times) to students either before $(n=220)$ or after $(n=178)$ the course midterm, which was conducted approximately six weeks after the start of the semester. By receiving the modules after the midterm (compared to those before the midterm), we could assess the impact of the modules on students' final examination performance for those (a) with less time to utilize the tools, and alternatively (b) with more of a barometer on their current level of performance in the course (i.e., those receiving the modules after the midterm should be more motivated to absorb the utility of the tools given - in some cases - rather lackluster midterm performance). Using a chi squared statistic, we evaluated whether the count of male and female respondents (who completed the modules) were evenly distributed between receipt either before or after the midterm. There were 73 and 59 males who received the modules before or after the midterm, respectively; and 146 and 119 females who received the modules before or after the midterm, respectively. Results found no significant deviation in the distribution of male and females by time of module delivery; $\chi^{2}(1, N=397)<1, p>.05$.

The module on time management aimed to improve student's ability to juggle many responsibilities such as academic assignments, a part time job, and family obligations while still maintaining a social life involving getting out into the community and pursuing various hobbies and interests. Thus, this module presented a discussion regarding procrastination and study problems related to time management and helped students to identify individual time management problems and implement strategies to solve them. Materials for this module were presented to assist students in the preparation of a semester study plan and activity schedules encompassing: preparing a master list of term requirements, setting up monthly calendars, developing a weekly schedule, and keeping a daily 'to do' list. Ultimately, these in-class lab tutorials emphasized that successful time management must be flexible and requires personal discipline.

The module on examination strategies aimed to teach students a new set of techniques to deal with testing in the college and/or university sector. The 
module provided students with information on how to write an objective examination and more specifically how to write a multiple-choice examination. The module also included a discussion regarding test anxiety and how to respond to shortanswer questions. The main objective of the module was for students to be able to effectively practice and apply general test-taking tips (e.g., trying an initial 'data dump,' reading directions and questions carefully, using time wisely, doing the easiest questions first, attempting every question and doing what you can, and actively reasoning through questions) and the nine principles of multiple-choice test-taking: (a) choosing the answer which the test marker intended, (b) anticipating the answer and then looking for it, (c) considering all the alternatives, (d) relating the options to the questions, (e) balancing options against each other, (f) using logical reasoning, (g) looking for special cue words, (h) knowing that the specific, detailed answers tend to be correct, and (i) using information obtained from other questions and options. Ultimately, this module aimed to reinforce to students that examinationtaking, like any other skill, must be practiced to be mastered.

At the completion of the two modular units, students then indicated their age and sex, and the extent to which they believed they were (a) interested in, (b) motivated by, and (c) focused on the two modules presented (as each was measured on a 5-point Likert scale, where $1=$ 'strongly disagree' and $5=$ 'strongly agree') (See Appendix for precise wording of the survey questions). Using this same scale, students also rated the extent to which they believed the two modules had the potential to be effective in their learning, and that they were presented in a way that could be readily incorporated into their own future studies. Finally, students were asked whether they believed the two modules were presented at an appropriate time in the scope of the course, or whether the two modules should have been presented either earlier or later than the midterm. Student midterm and final examination scores were merged with these survey data to compare module perceptions to student test performance. Upon completion of all materials, students were fully debriefed as to the nature and purpose of the study, including the experimental hypotheses. Following completion of data collection, students were alerted to the final results once available.

\section{Study-1: Results}

The significance level benchmark was set at alpha $=.05$ for all statistical analyses. However, we wish to caution the reader that given such a high sample size, significant effects may still be trivial in magnitude. Means and standard deviations can be found in Table 1. Upon analysis of the data, results showed no significant differences (in either midterm or examination performance, as well as survey responses) between students who completed the modules either before or after the midterm $(p s>.05)$. However, several key differences were significant when comparing students who completed the modules to those students who did not. Compared to students who did not complete the two modules, students given the two modular units performed significantly better on the course midterm, $t(806)=$ $4.39, p<.001$; and examination, $t(806)=3.88$, $p<.001$. Furthermore, when compared to students who received instruction in the evening sections of the same course (who did not receive the two modular units), students who completed the two modules performed significantly better on the course midterm, $t(657)=2.92, p=.004$; but not the final examination $(p>.05)$.

Using data from only those students who completed the two modules, an analysis of student assessment of modules to assist learning showed no significant differences $(p s>.05)$ in their perceptions of their relative (a) interest in (overall $M=3.49$, $S D=.94)$, (b) motivation by $(M=3.31, S D=.93)$, (c) focus on $(M=3.40, S D=.91)$, (b) effectiveness $(M=3.75, S D=.72)$, and (e) likelihood to use what was learned from the two modules in their future studies $(M=3.79, S D=.95)$. Using this same scale, students also rated the extent to which they believed the two modules had the potential to be effective in their learning, and that they were presented in a way that could be readily incorporated into their own future studies. Finally, whereas students who completed the two modules before the midterm were evenly split on believing the timing of modular presentation was appropriate $(49.8 \%)$ vs. wishing it to have been presented earlier in the course (50.2\%), a majority of students completing the modules after the midterm $(74.6 \%)$ wished that the two modules had been presented earlier in the course, $\chi^{2}(1$, $N=398)=23.97, p<.001$.

Table 1. Midterm and final examination means and standard deviations by group

\begin{tabular}{lccc}
\hline & & $\begin{array}{c}\text { Midterm } \\
\text { Mean (sd) }\end{array}$ & $\begin{array}{c}\text { Exam } \\
\text { Mean (sd) }\end{array}$ \\
Daytime Lectures & & & \\
Before Midterm & 211 & $63 \%^{\mathrm{a}}(.11)$ & $63 \%^{\mathrm{a}}(.14)$ \\
After Midterm & 170 & $62 \%^{\mathrm{a}}(.11)$ & $61 \%^{\mathrm{a}}(.13)$ \\
No Modules & 427 & $59 \%^{\mathrm{b}}(.13)$ & $58 \%^{\mathrm{b}}(.15)$ \\
& & & \\
Afternoon/Evening Lectures \\
No Modules & 278 & $60 \%^{\mathrm{b}}(.13)$ & $60 \%^{\mathrm{b}}(.16)$
\end{tabular}

Note. Means with identical superscripts are not significantly different $(p>.05)$. 


\section{Study-1: Discussion}

Overall, results showed that students who completed the two modules scored significantly higher on both their final examination and midterm scores than participants who did not complete the modules. Furthermore, the moment in the course when the two modules were presented (either before or after the course midterm) was not significantly related to student performance on either the course midterm or final examination scores. When students were asked if the two modules were presented at the appropriate time in the course, or they should have been presented earlier, students given the two modules before the course midterm were evenly divided (approximately 50-50). However, 3 of every 4 students who received the two modules after the course midterm believed the modules should have been presented earlier (even though time of module presentation made no significant difference in student performance).

Further consideration of these results raises additional questions. To begin, we failed to address the issue of assessing which students may have received learning modules or specialty training skills prior to our study, whether recently or in the distant past. This certainly can be assessed and either act as a covariate, or a filter variable that may exclude data from analysis. In addition, we are puzzled by one curious effect; the course midterm scores for students who received modules either before or after the midterm were significantly higher than scores for students who did not receive the two modules; however, some students did not receive their modules until after the midterm was administered, rendering them akin to those who had not received the two modules at any time in the semester. Whereas the final examination score is truly the main dependent variable of interest, it remains an odd effect, and warrants a replication.

\section{Study-2: Method}

\subsection{Participants}

With data collected in a new semester, the Introductory psychology course at the same midsized Canadian university consists of two large sections taught by the same instructor, and three afternoon/evening sections taught separately. Students in the two large sections were divided (by self-selection) into those who completed the modules $(n=352)$, either early $(n=209)$ or late $(n=143)$ in the term; and those who did not $(n=415)$. We again assessed whether age was at all different across the different sections of the course, and in this study found a significant effect, $F(3,482)=4.75, p=$ .003 ; follow-up Student-Neuman-Keuls multiple comparison procedures showed that students from one evening section were approximately 2-3 years older $(M=22.66)$ compared to the other three sections (wherein means ranged from 19.68 to 20.65 years). Average age across all groups was 20.41 years $(S D=5.12)$.

Two modules (viz. time management and examination taking strategies) were presented as a 25-minute face-to-face instructional unit, conducted six or nine weeks into the course. For comparison, 155 students from the afternoon class received the modules early, 86 students from one of the evening sections received them later; and 88 students from the other evening class did not receive any learning modules.

We also examined whether the distribution of males and females across the different conditions was consistent (see Table 2 for the distribution). The chi squared analysis was nonsignificant, $\chi^{2}$ (3, $N=487)=6.25, p=.10$. Whereas the male/female ratio in each section was approximately $65 \%$ female, there were slightly (though not significantly) by absolute count more females in the afternoon (nursing) section. Although we note there were a large number of missing entries for sex in both the afternoon and evening sections, these did not constitute critical omissions according to the hypotheses, and we proceeded with the analyses.

Table 2. Distribution of males and females who completed modules by course section

$\begin{array}{crrr}\text { Daytime Lectures } & & & \\ \text { Before Midterm } & 79 & 149 & 0 \\ \text { After Midterm } & 52 & 96 & 0 \\ \text { Afternoon Lectures } & & & \\ \quad \text { After Midterm } & 11 & 47 & 97 \\ \begin{array}{c}\text { Evening Lectures } \\ \text { Before Midterm }\end{array} & 20 & 33 & 33\end{array}$

At completion of the modules, students indicated their relative level of interest, motivation, and focus during the presentation, as well as the likelihood to use modules (as measured on a 5-point Likert scale: $1=$ strongly disagree $5=$ strongly agree). They also indicated the extent to which they believed the modules had the potential to be effective and were presented in a way that could be readily incorporated into their own studies. Finally, students were asked whether they believed the modules were presented at an appropriate time in the course or whether they should have been presented earlier or later. Student final examination scores were merged with these survey data to compare module perceptions to student test performance. 


\section{Study-2: Results}

There were no significant differences (in examination performance and survey perceptions) between students who completed the modules either before or after the midterm (that is, early or late in the semester; $p s>.05)$. However, some differences were significant when comparing students who completed the modules to those who did not (see Table 3). Compared to students who did not complete the modules, students who completed them performed significantly better on the examination, $t(1083)=2.95, p=.003$. Whereas there were no significant differences between students' examination scores in the two pre-midterm module sections $(p>.05)$, examination scores were higher for post-midterm module students in the daytime (compared to the evening) section; $t(291)=2.28$, $p=.023$.

Most students who completed the modules before the midterm believed it was an appropriate time of the year (61\%); 39\% wished it was earlier. However, a greater percentage $(75 \%)$ of students who received modules after the midterm wished they had received the presentation earlier, $\chi^{2}(1, N=483)=61.35$, $p<.001$. In addition, there were several significant differences in the survey based on when students received the two modules in the course of their semester.

Table 3. Midterm and final examination means and standard deviations by group

\begin{tabular}{|c|c|c|c|}
\hline & $\mathrm{N}$ & $\begin{array}{l}\text { Midterm } \\
\text { Mean (sd) }\end{array}$ & $\begin{array}{c}\text { Exam } \\
\text { Mean (sd) }\end{array}$ \\
\hline \multicolumn{4}{|l|}{ Daytime Lectures } \\
\hline Modules Before & 209 & $60 \%(.12)$ & $59 \%(.13)$ \\
\hline Modules After & 143 & $60 \%(.12)$ & $60 \%(.13)$ \\
\hline No Modules & 415 & $56 \%(.12)$ & $56 \%(.14)$ \\
\hline \multicolumn{4}{|c|}{ Afternoon/Evening Lectures } \\
\hline Modules (Before) & 150 & $59 \%(.11)$ & $57 \%(.12)$ \\
\hline Modules (After) & 81 & $61 \%(.11)$ & $57 \%(.12)$ \\
\hline No Modules & 88 & $61 \%(.12)$ & $58 \%(.12)$ \\
\hline
\end{tabular}

With respect to perceived interest in the modules delivered, students receiving the two modules before the course midterm were significantly less interested in the modules $(n=280, M=3.47, S D=1.02)$ compared to students receiving the two modules after the course midterm $(n=204, M=3.74, S D=.82)$; $t(477)=3.21, p<.001$. Moreover, with respect to perceived interest in the modules delivered, students receiving the two modules before the course midterm were significantly less motivated by the two modules ( $n=280, M=3.44, S D=.93$ ) compared to students receiving the two modules after the course midterm $(n=205, M=3.65, S D=.84) ; t(481)=2.56$, $p=.010$. Finally, with respect to their level of focus on the modules delivered, students receiving the two modules before the course midterm were significantly less focused on the modules $(n=278$, $M=3.50, S D=.93$ ) compared to students receiving the two modules after the course midterm $(n=206$, $M=3.66, S D=.81) ; t(477)=2.00, p=.046$.

\section{Study-2: Discussion}

Overall, the results of the second study mirror those of the first - participants who completed the two learning modules performed significantly better on the final examination than participants who did not complete the modules. The exact point in the course when the modules were presented (before/after the midterm) did not significantly affect student performance for their final examination. When asked if the two modules were presented at the appropriate time (or should have been presented earlier), almost three of five students believed the timing was suitable, whereas seventy-five percent of students given the two modules after the course midterm believed it should have been presented earlier (even though time of module presentation made no difference in students' final examination results). However, the time of modular presentation did affect students' perceptions of the value of the exercises, since each of the variables assessing perceived interest, motivation, and focus were significantly lower among those students who completed the two modules before the course midterm was administered; this suggests that students who performed poorly on the course midterm could well have taken the two modular units more seriously in an effort to finish the semester with a better overall score in the course.

\section{General Discussion}

Students who attend classes at various institutions of higher learning bring to bare a variety of educational foundations and skills; the nature of learning modules (examined presently) would ensure students receive a rich educational skill set by which to enhance effective learning in today's context of higher learning. It should be taken into consideration that the correlational nature of these studies precludes making any causal statements. There is a possibility that our results could have been influenced by several other factors such as personality differences, varying personal stress loads, motivational differences, and other forms of tutoring or mentoring. For example, there is some potential for the observed differences in test performance to be attributable to student motivation, which may be improved through appropriate training in general 
learning skills. That being said, given the introduction of critical control groups in this study, a similar range of these individual differences was likely present in both groups and thus we believe that the possibility is minimized.

Previous research has suggested that even brief training in time management, for example, can have beneficial effects [21]. Expanding this idea of training to delivering learning modules to first year students, for short-term effort the long-term gain appears evident. The skills acquired from these learning modules are those that ought to be offered prior to commencing post-graduate studies. The current study was undertaken to target the first-year student experience, and to offer and improve the necessary skills to ensure their success. Many instructors who greet the incoming students lament that many students lack the foundations of time management skills, and even fail to appreciate how to effectively take notes in class, study for tests, and how to take tests. These problems have been addressed for the first-year students in the Introductory Psychology class (as in the present study), offering learning modules for these vital skills within the laboratory sessions. Our results show that no matter when in the semester students receive the learning modules, their final examination performance was enhanced after receiving them. Given that past research has found that effective time management can lead to lower academic stress for example [14] further work and research should continue building more structurally sound foundations of student learning.

Based on previous research and based too on our own preliminary studies, the next question is to determine whether more students, across campus, could benefit from learning modules delivered in a convenient and widely accessible online format. We propose to develop a program that will adapt the previously in-lab learning modules into online learning modules format (e.g., time management, note taking, study, memorization, textbook reading and test taking skills). Further development of the presentation of such learning modules by including modular testing of knowledge retained and occasional maintenance sessions of learning module content would prove useful. This program would offer many future opportunities to educational institutions across the country by transforming students' learning experiences as they commence post-secondary studies.

It may be worthwhile to consider the typical means by which students today might acquire these valuable learning tools, if not through their own secondary school experience. It is not uncommon arguably that students - who seek much needed information concerning personal or academic matters - may withhold their questions for fear of social reproach at the admission they require help.
Specifically, to what extent would students be willing to cancel or refuse a social event due to their scheduled attendance at a workshop on examination strategies? At present, we cannot know. However, the better question centres around the more likely means by which students might acquire this information in a format less open to scrutiny and stigmatization. Students today would be more apt to select an anonymous online format; educational developers and researchers alike would do well to explore the development of online (anonymous) learning modules and seek further evidence that students who have completed the modules take away a keen advantage over students who have not.

Research and applied work have both shown that regardless of the types of delivery format, applicability of learning content appears to be an imperative issue to enhance student's learning experience in the context of higher education (15). The skills presented in our learning modules are not only applicable in nature but they are offered in an applicable way being offered during a course semester where such skills are evidently necessary. The goal for this area of research on teaching and learning should be to continue building more structurally sound foundations of student learning by offering basic learning skills (e.g., time management, examination taking strategies, reading, note taking, and study skills) at the onset of post-secondary studies in order to give students valuable tools in which to use to forge their future.

\section{Acknowledgements}

We would like to recognize the invaluable efforts of Meghan Rolfe in completing this work.

\section{References}

[1] C. J. Brahler, I. J. Quitadamo, and E. C. Johnson, "Student critical thinking is enhanced by developing exercise prescriptions using online learning modules." Advances in Physiology Education, 26, 2002, pp. 210-221.

[2] B. K. Britton, and A. Tesser, "Effects of timemanagement practices on college grades." Journal of Educational Psychology, 83, 1991, pp. 405-410.

[3] P. C. Brown, H. L., Roediger III, and M. A. McDaniel "Make it stick: The science of successful learning." Boston, MA: Belknap Harvard, 2013.

[4] R. L. Campbell, and L. W. Svenson, "Perceived level of stress among university undergraduate students in Edmonton, Canada." Perceptual and Motor Skills, 75, 1992, pp. 552-554.

[5] H. E. Douglas, M. Bore, and D. Munro, "Coping with university education: The relationships of time management behaviour and work engagement with the five 
factor model aspects." Learning and Individual Differences, 45, 2016, pp. 268-274.

[6] R. García-Ros, F. Pérez-Gonźalez, and E. Hinojosa, "Assessing time management skills as an important aspect of student learning: The construction and evaluation of a time management scale with Spanish high school students." School Psychology International, 25, 2004, pp. 167-183.

[7] A. Häfner, V. Oberst, and A. Stock, “Avoiding procrastination through time management: An experimental intervention study." Educational Studies, 40, 2014, pp. 352-360.

[8] E. A. Holdaway, and K. R. Kelloway, "First year at university: Perceptions and experiences of students." Canadian Journal of Higher Education, 17, 1987, pp. 4763.

[9] M. Lincoln, B. Adamson, and T. Covic, "Perceptions of stress, time management and coping strategies of speech pathology students on clinical placement." Advances in Speech-Language Pathology, 6, 2004, pp. 91-99.

[10] D. G., Longman, and R. H. Atkinson, "College Learning and Study Skills. St. Paul, MN: West, 1988.

[11] T. H. Macan, "Time management: Test of a process model." Journal of Applied Psychology, 79, 1994, pp. 381391.

[12] T. H. Macan, C. Shahani, R. L. Dipboye, and A. P. Phillips, "College students' time management: Correlations with academic performance and stress." Journal of Educational Psychology, 82, 1990, pp. 760-768.

[13] C. MacCann, G. J. Fogarty, and R. D. Roberts, "Strategies for success in education: Time management is more important for part-time than full-time community college students." Learning and Individual Differences, 22, 2012, pp. 618-623.

[14] R. Misra and M. McKean, "College students' academic stress and its relation to their anxiety, time management, and leisure satisfaction." American Journal of Health Studies, 16, 2000, pp. 41-51.

[15] L. Murtagh, "Enhancing preparation for Higher Education." Practitioner Research in Higher Education, 6, 2012, pp. 31-39.

[16] L. B. Nilson, "Creating self-regulated learners: Strategies to strengthen students' self-awareness and learning skills." Sterling, V A: Stylus Publishing, 2014.

[17] C. M. P. O'Tuathaigh, E. Duggan, A. S. Khashan, G. B. Boylan, and S. O'Flynn, "Selection of student-selected component (SSCs) modules across the undergraduate curriculum: Relationship with motivational factors." Medical Teacher, 34, 2012, pp. 813-820.

[18] M. Peat, C. E. Taylor, and S. Franklin, "Re- engineering of undergraduate science curricula to emphasize development of lifelong learning skills." Technology in Education, 42, 2005, pp. 135-146.

[19] A. Pehlivan, "The effect of the time management skills of students taking a financial accounting course on their course grades and grade point averages." International Journal of Business and Social Science, 4, 2013, pp. 196-203.

[20] K. Sevari, and M. Kandy, "Time management skills impact on self-efficacy and academic performance." Journal of American Science, 7, 2011, pp. 720-726.

[21] A. E. Woolfolk and R. L. Woolfolk, "Time management: An experimental investigation." Journal of School Psychology, 21, 1986, pp. 267-275. 


\section{Appendix}

\section{Survey Questions}

1. To what extent are you motivated to achieve high grades at the University of Windsor

\begin{tabular}{l|lllll|l} 
Not at all & 1 & 2 & 3 & 4 & 5 & Extremely motivated
\end{tabular}

2. How confident are you that you will achieve high grades at the University of Windsor? (Circle one of the following numbers listed below).

Not at all | \begin{tabular}{lllll|l}
1 & 2 & 3 & 4 & 5 & Extremely confident
\end{tabular}

3. How well do you believe high school prepared you to achieve high grades at the University of Windsor? (Circle one of the following numbers listed below).

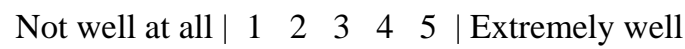

4. Have you been presented with learning strategies (e.g., time management skills, tools for better test performance and note-taking, etc.) in the past? If so, please list which learning strategies you received:

5. Please estimate your incoming high school grade point average (based on your final year) $\%$

6. In two or more sentences, explain why have you decided to undertake these learning modules today?

7. Have you ever received instruction on learning modules (study skills) at the University?

8. Were the modules presented at an appropriate time in the semester? (Check an option below)

Yes, they were presented at an appropriate time

No, they should have been presented earlier in the semester

No they should have been presented later in the semester 